\title{
Modulation of airway responsiveness by the airway epithelium in humans: putative mechanisms
}

\author{
A. R. HULSMANN* and J. C. DE JONGSTE \\ Department of Paediatrics, Subdivisions of Neonatology* and Pediatric Respiratory Medicine, \\ Sophia Children's Hospital, Rotterdam, The Netherlands.
}

\section{Introduction}

The airway epithelium forms the interface between the respiratory system and the external environment and consists of ciliated and non-ciliated cells tightly attached to each other and to the basement membrane [1]. In bronchial asthma, areas of airway epithelium become damaged and the degree of epithelial damage correlates with the level of bronchial responsiveness $[2,3]$. Inflammatory cells present in the asthmatic airway mucosa may contribute to the epithelial damage by the production of oxidants, proteases and cationic proteins [1,3-5]. In addition, airway epithelium may be disrupted by an increased subepithelial hydrostatic pressure caused by oedema of the inflamed airway wall [6]. Several mechanisms have been proposed to explain the relationship between epithelial damage and airway hyperresponsiveness. These include, firstly, a reduced production of epithelium-derived relaxing factors (EpDRF) [7] and secondly, a decreased metabolization of bronchoconstricting mediators and neurotransmitters by the damaged epithelial cells [8]. Thirdly, loss of epithelial integrity may increase airway permeability and provide easy access of bronchoactive mediators to the airway smooth muscle [9]. Finally, epithelial damage may expose intra-epithelial sensory (peptidergic) nerves. Excitation of these sensory nerves by inflammatory mediators may lead to a local reflex bronchoconstriction via release of neuropeptides or tachykinins [10]. The above-mentioned hypothetical mechanisms are schematically shown in Figure 1 and will be discussed in some detail in the present review.

\section{Production of bronchoactive mediators by the airway epithelium}

After the discovery of endothelium-derived relaxing factor (EDRF, now identified as nitric oxide [11]) in blood vessels it was hypothesized that a similar factor might be produced by the airway epithelium. In asthma,

Correspondence: A. R. Hulsmann, Department of Neonatology, Sophia Children's Hospital, Dr Molewaterplein 60, 3015 GJ Rotterdam, The Netherlands. this epithelium-derived relaxing factor (EpDRF) might not be produced in sufficient amounts to keep the airway smooth muscle in a relaxed state and thereby contribute to bronchoconstriction. Several candidates for EpDRF have been put forward including arachidonic acid metabolites [7] and, more recently, NO [12,13].

In vitro, human airway epithelial cells are indeed able to metabolize arachidonic acid to both cyclooxygenase and lipoxygenase products [14]. However, the cyclooxygenase products thromboxane $\mathrm{A}_{2}\left(\mathrm{TxA}_{2}\right)$, prostaglandin $\mathrm{D}_{2}\left(\mathrm{PGD}_{2}\right)$, and prostaglandin $\mathrm{F}_{2 \alpha}\left(\mathrm{PGF}_{2 \alpha}\right)$ constrict human airway smooth muscle both in vivo and in vitro through activation of the thromboxane prostanoid (TP)receptor $[15,16]$. Prostaglandin $\mathrm{E}_{2}\left(\mathrm{PGE}_{2}\right)$ and prostaglandin $\mathrm{I}_{2}\left(\mathrm{PGI}_{2}\right.$, prostacyclin) may relax or contract airway smooth muscle depending on which prostanoid receptor subtype is involved [16].

5-Lipoxygenase is the most important enzyme of the lipoxygenase pathway. It catalyzes the formation of the unstable leukotriene $\mathrm{LTA}_{4}$ which is further converted to $\mathrm{LTC}_{4}, \mathrm{LTD}_{4}$, and $\mathrm{LTE}_{4}$ [14]. Leukotrienes, especially $\mathrm{LTC}_{4}$ and $\mathrm{LTD}_{4}$, are potent constrictors of airway and vascular smooth muscle and increase microvascular permeability and mucus secretion [17]. Because all lipoxygenase products and most cyclooxygenase products contrast human airways it is not likely that they act as EpDRF. Indeed, human isolated airways relax to endogenous prostanoids only in the presence of a TP-receptor blocking drug [18].

The highly reactive gas nitric oxide (NO) is formed from L-arginine by the enzyme NO-synthase (NOS) which has been demonstrated in human airway epithelium [19]. NO relaxes smooth muscle through activation of soluble guanylate cyclase and elevation of intracellular cyclic guanosine monophosphate (cGMP) [19]. Recently, it was suggested that analogous to the vascular endothelium, the airway epithelium produces NO that may act as EpDRF $[12,13]$. In the blood vessels, the NO-producing endothelium directly lines vascular smooth muscle. Epithelium-derived NO, however, has to pass a dense subepithelial vascular plexus to reach airway smooth muscle. 


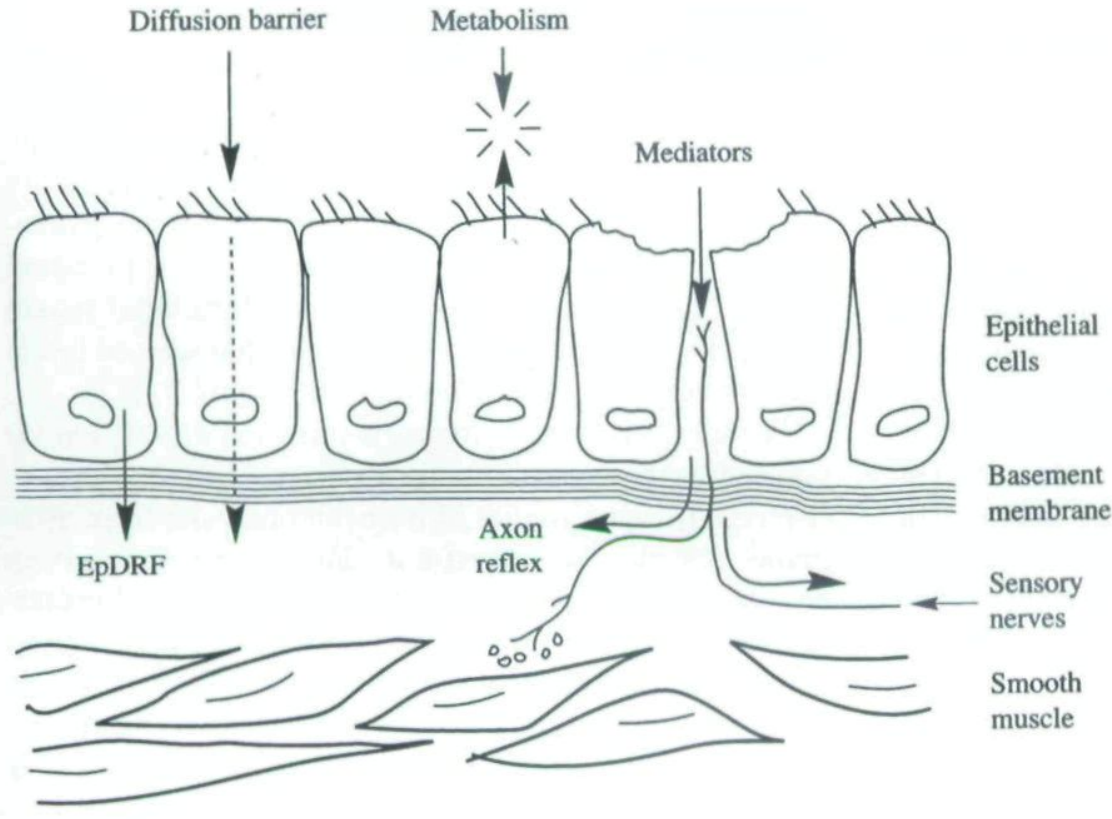

Fig. 1. Putative mechanisms explaining the relationship between epithelial damage and airway hyperresponsiveness. EpDRF $=$ epithelium-derived relaxing factor.
Because NO eagerly binds to haemoglobin [11] and relaxes airway smooth muscle only at high concentrations [20], it is not likely that in vivo epithelial NO molecules will reach airway smooth muscle in sufficient amounts to produce airway smooth muscle relaxation. Indeed, in healthy humans, inhaled NO produces a potent vasodilation of pulmonary vessels [21] but only a slight bronchodilation [22]. It can be hypothesized, therefore, that products released by the airway epithelium may have a more important modulatory role on the airway mucosal bloodflow than on airway smooth muscle responsiveness and this may be an important determinant of airway responsiveness as well.

\section{Metabolic functions of the airway epithelium}

The airway epithelium not only provides a physical barrier restricting access of inhaled noxious stimuli but also actively defends the underlying submucosa: bronchoactive peptides like tachykinins and kinins are degraded by epithelial membrane-bound neutral endopeptidase (NEP) and angiotensin-converting enzyme (ACE) $[8,10]$. Similarly, the neurotransmitter acetylcholine and the inflammatory mediator histamine are inactivated by epithelium-derived acetylcholinesterase and $\mathrm{N}$-methyltransferase, respectively [23,24]. Oxidants, either inhaled or produced by inflammatory cells, are inactivated by antioxidants in the epithelial lining fluid and by the intracellular enzymes superoxide dismutase, catalase and glutathione peroxidase $[25,26]$. Airway epithelial cells may also contribute to host defence by modulating the local mucosal immune response: Inflammatory cells are recruited into the airway lumen by chemotactic mediators and cytokines released by epithelial cells [27,28]. Furthermore, epithelial cells are able to express specific receptors called adhesion molecules on their surface which enable them to interact with migrating inflammatory cells $[27,28]$.

In experimental settings removal of the epithelium or addition of specific enzyme inhibitors causes hyperresponsiveness of the airway smooth muscle to inflammatory mediators, and neurotransmitters which suggests an important metabolic role of the airway epithelium $[8,18,23]$. This is supported by the finding that viral infections and environmental pollutants such as cigarette smoke and toluene diisocyanate decrease epithelial NEP activity and increase airway responsiveness [29].

However, airway hyperresponsiveness cannot be explained by impaired metabolic function of the damaged epithelium alone. For instance, NEP has also been demonstrated on sub-epithelial tissues both functionally and by immunohistochemistry $[18,30]$. Moreover, although asthmatic patients are hyperresponsive to inhaled neuropeptides, no evidence for reduction of NEP activity was found in these patients $[31,32]$ perhaps because there are sufficient non-epithelial sources of NEP in the airways. Thus, although the airway epithelium has the potential to act as a metabolic site where bronchoconstrictive stimuli are inactivated, evidence that this metabolic function deteriorates in asthma is lacking. 


\section{Epithelium as a diffusion barrier}

The airway epithelium forms a barrier against leakage of water and solutes into the airways and prevents penetration of inhaled material to the airway interstitium [6]. This barrier function of the epithelium is achieved through several adhesive mechanisms which are shown in Figure 2 [1,33]. The desmosome (macula adherens) and the intermediate junction (zonula adherens) maintain cell-to-cell adhesion. Intermediate junctions form a ring-like adhesive mechanism around the cell to which adhesion molecules have been localized $[1,33]$. Hemidesmosomes consist of peptides called integrins and anchor the basal cells to the basement membrane. The tight junction (zonula occludens) is a narrow belt-like structure of unknown composition surrounding each cell at the apical pole. Tight junctions are considered as a major component of the epithelial barrier and regulate paracellular transport of large and hydrophilic molecules [33]. The permeability of tight junctions can be modulated by proteases, cytokines, eosinophil- and neutrophil-derived proteins and bacterial products [34]. Because of their important function, evidence of damage to tight junctions has been sought in disease states like pulmonary oedema and asthma. In asthmatic patients, increased airway permeability to inhaled hydrophilic tracer molecules was found [35] and electronmicroscopical studies of bronchial biopsies from asthmatic patients revealed opening of tight junctions and widening of intercellular spaces in the airway epithelium [3]. Moreover, the frequency of opening of tight junctions correlated with eosinophil infiltration and the degree of bronchial responsiveness suggesting a causal relationship [3]. These observations are supported by studies of human airways in vitro: luminal exposure of human airways to oxidants or cationic proteins increased both airway responsiveness and permeability to the hydrophilic drugs (Figure 3) [36,37]. Histological examination of these airways revealed widening of intercellular spaces and opening of tight junctions in areas that seemed intact on light microscopical examination (Figure 4) [37].

There are, however, arguments against loss of barrier function as the main mechanism of bronchial hyperresponsiveness. In some studies of bronchial biopsies from asthmatic patients no structural damage to the airway epithelium was found although the patients were hyperresponsive to inhaled methacholine [38]. Similarly, airway hyperresponsiveness in laboratory animals exposed to cationic proteins was caused by the release of bradykinin and no evidence for epithelial damage was found [39]. Furthermore, although bacterial toxins may increase tight junction permeability [34], airway hyperresponsiveness is not typically found during bacterial pneumonia.

Viral infections, on the other hand, induce airway hyperresponsiveness [40] and although this has been attributed to virus-induced epithelial damage, recent evidence suggests that airway hyperresponsiveness after viral infections may be related to a deficiency in NO [41]. Finally, studies in guinea-pigs in vivo have shown that a denuded basement membrane is soon covered by a plasma-derived gel followed by flattening and migration of secretory and ciliated epithelial cells over the denuded

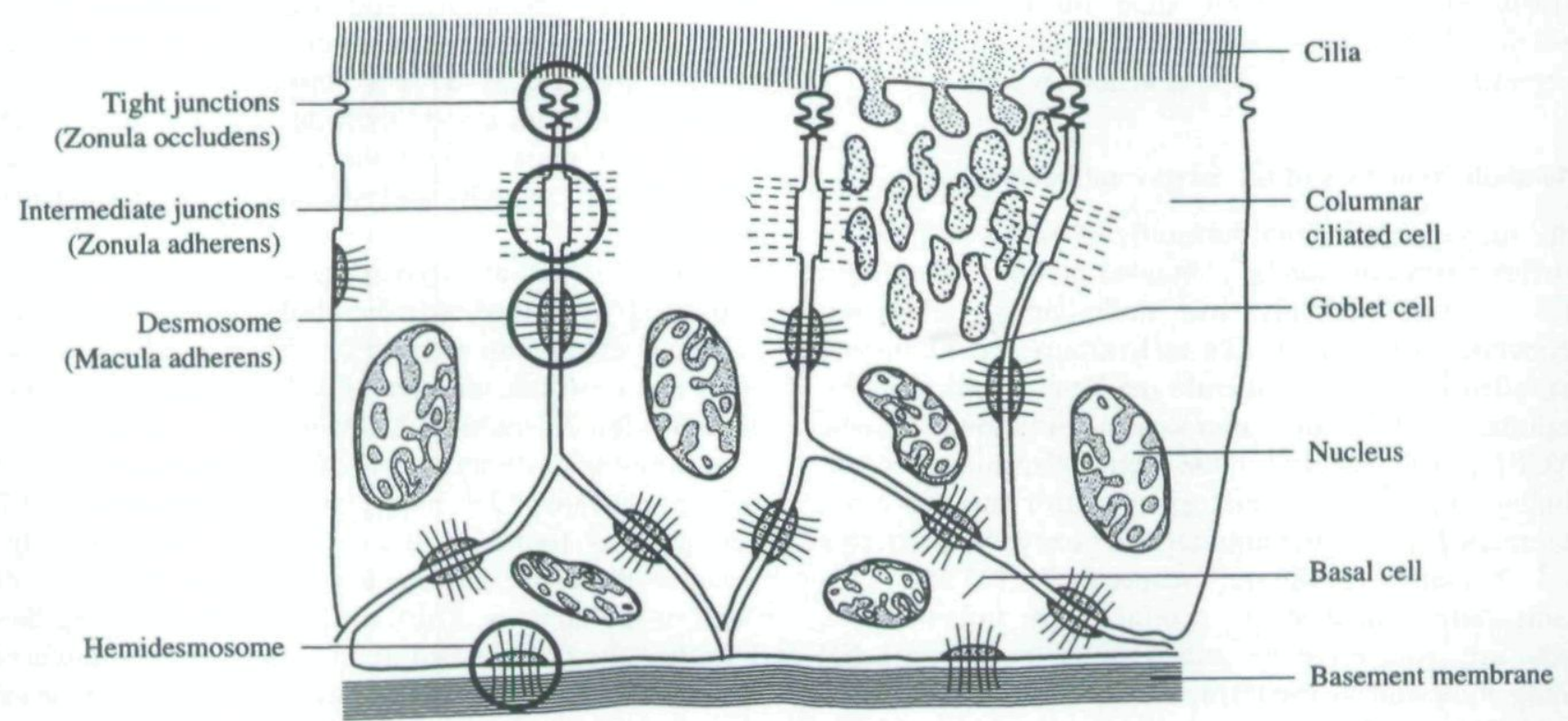

Fig. 2. Schematic representation of the adhesion of the bronchial epithelium. 


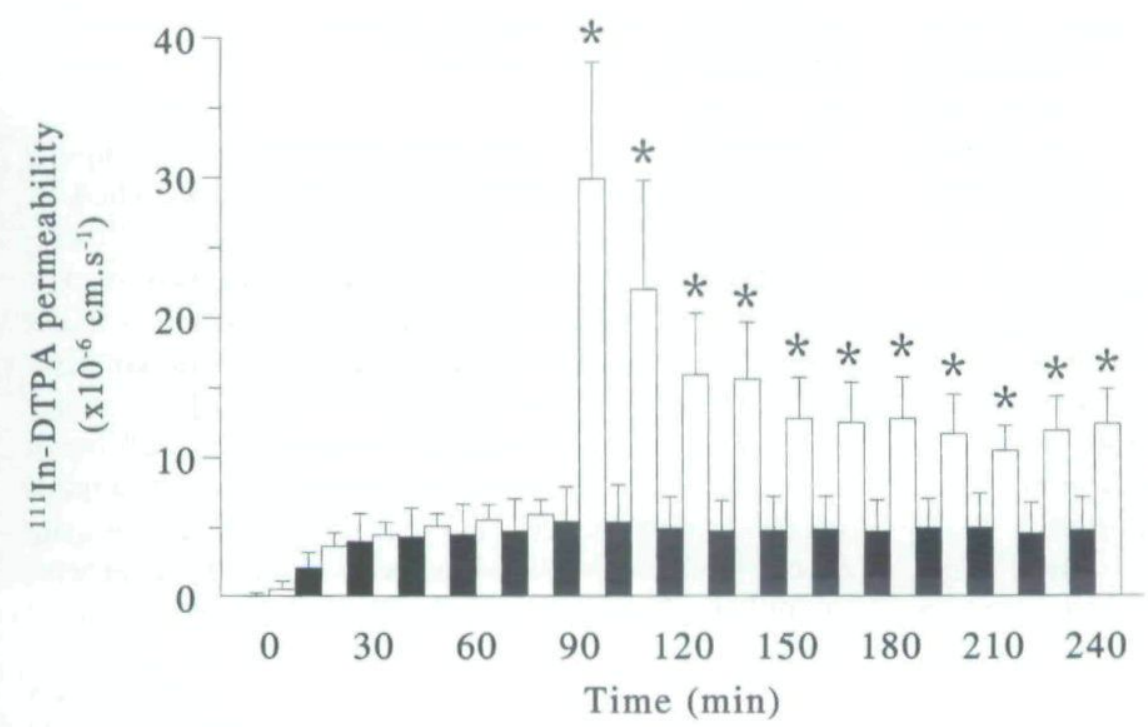

Fig. 3. Time courses of the effect of luminally applied hydrogen peroxide $\left(\mathrm{H}_{2} \mathrm{O}_{2}\right)$ on permeability of human isolated airways to ${ }^{111}$ In-DTPA $(n=10)$. $\square=$ exposure to $\mathrm{H}_{2} \mathrm{O}_{2} 110 \mathrm{mmol} / \mathrm{l}$ at $\mathrm{T}=90 \mathrm{~min}$ for $15 \mathrm{~min}$. $\mathbf{m}=$ controls not exposed to $\mathrm{H}_{2} \mathrm{O}_{2},{ }^{*} P<0.05$ compared with controls. Reproduced with permission from Hulsmann et al. (1996) [37].

area [6]. Thus, in vivo, the barrier function of the epithelium may be maintained or restored rapidly after epithelial damage. However, these repair mechanisms have not been studied in human airways.

\section{Exposure of intraepithelial sensory nerves with release of tachykinins}

In animal and human airways, superficial unmyelinated sensory nerves (C-fibres or peptidergic nerves) have been identified that terminate in the airway epithelium. These nerves contain sensory neuropeptides such as the tachykinins substance P (SP) and neurokinin A (NKA) which may be the neurotransmitters of the excitatory non-adrenergic, noncholinergic (NANC) nervous system [10,42]. In the guinea pig, excitation of these nerve fibres by chemical and physical stimuli may produce retrograde (antidromic) impulses that result in local release of tachykinins (Figure 1) [43-45].

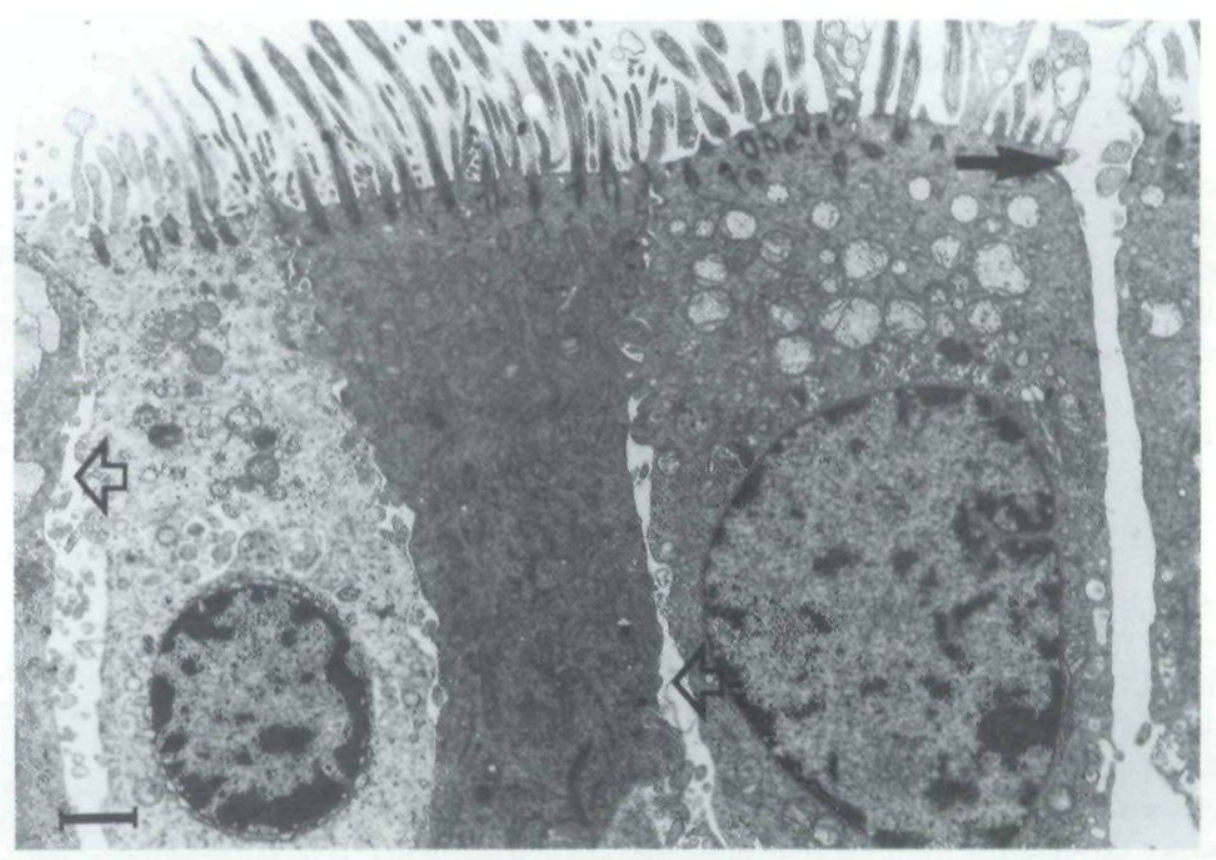

Fig. 4. Transmission electron photomicrograph of human bronchial epithelium after exposure to $100 \mathrm{mmol} / 1 \mathrm{H}_{2} \mathrm{O}_{2}$ for $15 \mathrm{~min}$. Open arrows indicate widening of intercellular spaces; closed arrows depict an opened tight junction area, $\mathrm{bar}=1 \mu \mathrm{m}$. Reproduced with permission from Hulsmann et al. (1996) [37]. 
Tachykinins induce airway smooth muscle contraction, mucus secretion, vascular hyperpermeability and dilation of tracheal and bronchial blood vessels, and stimulate and attract inflammatory cells [10,42-45]. Because of these effects, called 'neurogenic inflammation', tachykinins have been implicated in the pathophysiology of asthma. Compared to guinea-pig airways, however, human airways contain much less tachykinincontaining nerve fibres [45] and less tachykinin receptors [46] and this would suggest that in human airways neurogenic inflammation may be less relevant. Recently, however, an increased SP-immunoreactivity in bronchoalveolar fluid and sputum has been reported in asthmatics $[47,48]$. Furthermore, inhalation of a tachykinin receptor antagonist partly prevented bronchoconstriction induced by the C-fibre-stimulating inflammatory mediator bradykinin [49].

Although these studies suggest that endogenous tachykinins are released during an asthmatic attack, they do not prove that these tachykinins are released by nerves and not, for instance, by inflammatory cells present in the airways. Therefore, we investigated the effect of the selective C-fibre-stimulating drug capsaicin [50] on human isolated airways. Capsaicin caused small contractile responses in human airways. In addition, capsaicin induced the release of the tachykinins SP and NKA by these airway preparations, which could be inhibited by the neural conductance blocker tetrodotoxin (TTX) [51]. This indicates that the tachykinins were indeed released by nerve fibres, probably through a local axon reflex mechanism. Although in our experiments with human isolated airways these local axon reflexes did not produce important bronchoconstriction, in vivo local axon reflexes may produce other features of 'neurogenic inflammation' such as tracheobronchial vasodilatation, and inflammation and oedema of the airway mucosa. These processes may increase airway wall thickness and thereby contribute to airway narrowing $[52,53]$. Further studies are necessary to elucidate the relevance of local axon reflexes in vivo in asthmatic patients.

\section{Conclusions}

From the present experimental evidence, the relationship between airway epithelial damage and airway hyperresponsiveness cannot be easily attributed to one of the putative mechanisms mentioned in our introduction. Firstly, the airway epithelium releases many substances that may influence airway smooth muscle tone, but the functional importance of an epithelium-derived relaxing factor analogous to EDRF/NO in the vasculature is still not confirmed in humans. Epithelium-derived factors may indirectly contribute to airway narrowing by modulating airway mucosal bloodflow and enhancing inflammation. Further studies, both in vitro and in vivo, are required to confirm this hypothesis.

Secondly, many studies have shown that the airway epithelium degrades bronchoactive substances. There is, however, no conclusive evidence for a diminished metabolic function of the airway epithelium in asthma. The third hypothetical mechanism is supported by the demonstration of increased permeability of human asthmatic airways in vivo. Furthermore, epithelial damage increases both airway responsiveness and permeability of isolated human airways. Studies in laboratory animals suggest maintainence or rapid repair of the barrier function after epithelial damage in vivo and this process of epithelial repair should also be investigated in human airways in vivo.

Finally, recent evidence suggests that local axon reflex mechanisms which release tachykinins are present in human airways. The functional relevance of these axon reflexes for asthmatic airway inflammation and narrowing in vivo remains to be elucidated. From the data reviewed, it is evident that the human airway epithelium is a source of many active substances that may influence airway smooth muscle tone and airway reactivity directly or indirectly. The precise mechanisms and clinical relevance of these putative factors require further investigation.

\section{References}

1 Montefort S, Herbert CA, Robinson C, Holgate ST. The bronchial epithelium as a target for inflammatory attack in asthma. Clin Exp Allergy 1992; 22:511-20.

2 Jeffery PK, Wardlaw AJ, Nelson FC, Collins JV, Kay AB. Bronchial biopsies in asthma: an ultrastructural, quantitative study and correlation with hyperreactivity. Am Rev Respir Dis 1989; 140:1745-53.

3 Ohashi Y, Motojima S, Fukuda T, Makino S. Airway hyperresponsiveness, increased intracellular spaces of bronchial epithelium, and increased infiltration of eosinophils and lymphocytes in bronchial mucosa in asthma. Am Rev Respir Dis 1992; 145: 1469-76.

4 Bousquet J, Chanez P, Vignola AM, Lacoste JY, Michel F-B. Eosinophilic inflammation in asthma. Am J Respir Crit Care Med 1994; 150:S33-8.

5 Coyle AJ, Uchida D, Ackerman SJ, Mitzner W, Irvin CG, Role of cationic proteins in the airway hyperresponsiveness due to airways inflammation. Am J Respir Crit Care Med 1994; 150:S63-71.

6 Persson CGA, Anderson M, Greiff L et al. Review: airway permeability. Clin Exp Allergy 1995; 23:807-14.

7 Farmer SG, Hay DWP. Airway epithelial modulation of smooth muscle function: the evidence for epitheliumderived inhibitory factor. In: Farmer SG, Hay, DWP, eds. The airway epithelium: physiology, pathophysiology and 
pharmacology. New York: Marcel Dekker Inc. 1991:43784.

8 Lilly CM, Drazen JM, Shore SA. Minireview: peptidase modulation of airway effects of neuropeptides. Proc Soc Exp Biol Med 1993; 203:388-404.

9 Munakata M, Mitzner W. The protective role of airway epithelium. In: Farmer SG, Hay DWP, eds. The airway epithelium: physiology, pathophysiology and pharmacology. New York: Marcel Dekker Inc. 1991:545-64.

10 Joos GF, Germonpré PR, Kips JC, Peleman RA, Pauwels RA. Sensory neuropeptides and the human lower airways: present state and future directions. Eur Respir J 1994; 7:1161-71.

11 Moncada S, Palmer RMJ, Higgs EA. Nitric oxide: physiology, pathophysiology, and pharmacology. Pharmacol Rev 1991; 43:109-42.

12 Nijkamp FP, Van der Linde HJ, Folkerts G. Nitric oxide synthesis inhibitors induce airway hyperresponsiveness in the guinea pig in vivo and in vitro. Am Rev Respir Dis 1993; 148:727-34.

13 Nijkamp FP, Folkerts G. Review: nitric oxide and bronchial reactivity. Clin Exp Allergy 1994; 24:905-14.

14 Holtzman MJ. Arachidonic acid metabolism in airway epithelial cells. Annu Rev Physiol 1992; 54:303-29.

15 Coleman RA, Sheldrick RLG. Prostanoid-induced contraction of human bronchial smooth muscle is mediated by TP receptors. Br J Pharmacol 1989; 96:688-92.

16 Coleman RA, Smith WL, Narumiya S. Classification of prostanoid receptors: properties, distribution, and structure of the receptors and their subtypes. Pharmacol Rev 1994; 46:205-29.

17 Hay DWP, Torphy TJ, Undem BJ. Cysteinyl leukotrienes in asthma: old mediators up to new tricks. Trends Pharmacol Sci 1995; 16:304-9.

18 Hulsmann AR, Raatgeep HR, Saxena PR, Kerrebijn KF, De Jongste JC. Bradykinin-induced contraction of human peripheral airways mediated by both bradykinin $\mathbf{B}_{2}$ and thromboxane prostanoid receptors. Am J Respir Crit Care Med 1994; 150:1012-8.

19 Gaston B, Drazen JM, Loscalzo J, Stamler JS. State of the art: the biology of nitrogen oxides in the airways. Am J Respir Crit Care Med 1994; 149:538-51.

20 Zhao W, Guenard H. Effect of nitric oxide on in vitro responsiveness of bovine bronchus and pulmonary vessels. Eur Respir J 1995; 8:755-61.

21 Frostell CG, Blomqvist H, Hedenstierna G, Lundberg J, Zapol WM. Inhaled nitric oxide selectively reverses human hypoxic vasoconstriction without causing systemic vasodilation. Anesthesiology 1993; 78:427-35.

22 Högman M, Frostell CG, Hedenström H, Hedenstierna G. Inhalation of nitric oxide modulates adult human bronchial tone. Am Rev Respir Dis 1993; 148:1474-8.

23 Koga Y, Satoh S, Sodeyama N et al. Role of cholinesterase in airway epithelium-mediated inhibition of acetylcholineinduced contraction of guinea-pig isolated trachea. Eur $\mathbf{J}$ Pharmacol 1992; 220:141-6.

24 Okayama M, Yamauchi K, Sekizawa K et al. Localization of histamine N-methyltransferase messenger RNA in human nasal mucosa. J Allergy Clin Immunol 1995; 95:96-102.

25 Heffner JE, Repine JE. Pulmonary strategies of antioxidant defence. Am Rev Respir Dis 1989; 140:531-4.

26 Avissar N, Finkelstein JN, Horowitz S et al. Extracellular glutathione peroxidase in human lung epithelial lining fluid and in lung cells. Am J Physiol 1996; 270:L173-82.

27 Raeburn D, Webber SE. Review: proinflammatory potential of the airway epithelium in bronchial asthma. Eur Respir J 1994; 7:2226-33.

28 Thompson AB, Robbins RA, Romberger DJ, Sisson JH, Spurzem JR, Teschler H, Rennard SI. Immunological functions of the pulmonary epithelium. Eur Respir J 1995; $8: 127-49$.

29 Borson DB. Roles of neutral endopeptidase in airways. Am J Physiol 1991; 260:L212-25.

30 Baraniuk JN, Ohkubo K, Kwon OJ et al. Localization of neutral endopeptidase (NEP) mRNA in human bronchi. Eur Respir J 1995; 8:1458-64.

31 Cheung D, Timmers MC, Zwinderman AH et al. Neutral endopeptidase activity and airway hyperresponsiveness to neurokinin $\mathrm{A}$ in asthmatic subjects in vivo. Am Rev Respir Dis 1993; 148:1467-73.

32 Joos GF, Kips JC, Pauwels RA. Editorial: a role for neutral endopeptidase in asthma? Clin Exp Allergy 1994; 24:91-3.

33 Schneeberger EE, Lynch RD. Structure, function, and regulation of cellular tight junctions. Am J Physiol 1992; 262:L647-61.

34 Lewis SA, Berg JR, Kleine TJ. Modulation of epithelial permeability by extracellular macromolecules. Physiol Rev 1995; 75:561-89.

35 Ilowite JS, Bennett WD, Sheets MS, Groth ML, Nierman DM. Permeability of bronchial mucosa to ${ }^{99 m}$ Tc-DTPA in asthma. Am Rev Respir Dis 1989; 139:1139-43.

36 Hulsmann AR, Raatgeep HC, Den Hollander JC et al. Oxidative damage produces hyperresponsiveness of human peripheral airways. Am J Respir Crit Care Med 1994; 149:519-25.

37 Hulsmann AR, Raatgeep HC, Den Hollander JC et al. Permeability of human peripheral airways increases after exposure to hydrogen peroxide and poly-L-arginine. Am J Respir Crit Care Med 1996; 153:841-6.

38 Lozewicz S, Wells C, Gomez E et al. Morphological integrity of the bronchial epithelium in mild asthma. Thorax 1990; 45:12-5.

39 Coyle AJ, Ackerman SJ, Burch R, Proud D, Irvin CG. Human eosinophil-granule major basic protein and synthetic polycations induce airway hyperresponsiveness in vivo dependent on bradykinin generation. J Clin Invest 1995; 95:1735-40.

40 Busse WW. Viral infections in humans. Am J Respir Crit Care Med 1995; 151:1675-7.

41 Folkerts G, Van der Linde HJ, Nijkamp FP. Virus-induced airway hyperresponsiveness in guinea pigs is related to a deficiency in nitric oxide. J Clin Invest 1995; 95:26-30.

42 Barnes PJ, Baraniuk JN, Belvisi MG. Neuropeptides in the 
respiratory tract. Part I. Am Rev Respir Dis 1991; 144:1187-98.

43 Lou YP. Regulation of neuropeptide release from pulmonary capsaicin-sensitive afferents in relation to bronchoconstriction. Acta Physiol Scand Suppl. 1993; 612:1-8.

44 Maggi CA. Tachykinins and calcitonin gene-related peptide (CGRP) as co-transmitters released from peripheral endings of sensory nerves. Prog Neurobiol 1995; 48:1-98.

45 Martling C-R. Sensory nerves containing tachykinins and CGRP in the lower airways. Functional implications for bronchoconstriction, vasodilatation and protein extravasation. Acta Physiol Scand 1987; 563:S1-57.

46 Walsh DA, Salmon M, Featherstone R et al. Differences in the distribution and characteristics of tachykinin $\mathrm{NK}_{\text {, }}$ binding sites between human and guinea pig lung. $\mathrm{Br} \mathrm{J}$ Pharmacol 1994; 113:1407-15.

47 Nieber K, Baumgarten CR, Rathsack R et al. Substance P and $\beta$-endorphin-like immunoreactivity in lavage fluids of subjects with and without allergic asthma. J Allergy Clin Immunol 1992; 90:646-52.
48 Tomaki M, Ichinose M, Miura M et al. Elevated substance $\mathrm{P}$ content in induced sputum from patients with asthma and patients with chronic bronchitis. Am J Respir Crit Care Med 1995; 151:613-7.

49 Ichinose M, Nakajima N, Takahashi T et al. Protection against bradykinin-induced bronchoconstriction in asthmatic patients by neurokinin receptor antagonists. Lancet 1992; 340:1248-51.

50 Holzer P. Capsaicin: cellular targets, mechanisms of action, and selectivity for thin sensory neurons. Pharmacol Rev 1991; 43:143-201.

51 Hulsmann AR, Raatgeep HR, Zijlstra FJ, Saxena PR, De Jongste JC. Capsaicin induces bronchoconstriction and tachykinin release in human isolated airways, submitted.

52 Brown RH, Zerhouni EA, Mitzner W. Airway edema potentiates airway reactivity. J Appl Physiol 1995; 79:1242-8.

53 Regnard J, Beji M, Dessanges JF et al. Is tracheobronchial vasodilation a component of bronchial hyperresponsiveness? Eur Respir J 1990 3:678-85s. 
This document is a scanned copy of a printed document. No warranty is given about the accuracy of the copy. Users should refer to the original published version of the material. 